\title{
OBSERVATIONS UPON THE INTERFACE BETWEEN BONE AND POLYMETHYLMETHACRYLATE CEMENT
}

\author{
M. A. R. FREEMAN, G. W. BRADLEY, P. A. REVELL
}

From the London Hospital, London

\begin{abstract}
The occurrence of a radiolucent line at the interface of bone and cement in total joint prostheses is a frequently observed, although little understood, phenomenon. Because of an operative technique utilised in instances of bone loss, we have, within a single implant mass used in each of a series of 18 total knee replacements, been able to observe two separate interfaces, one between bone and cement and the other between bone and cobalt chrome. The average period of observation was 32 months. All of the knees except one demonstrated a lucency at the bone-cement interface; only one of the knees had a similar lucency at the bone- $\mathrm{CoCr}$ interface. One of the knees was studied histologically. In the light of the universal observation of macrophages at bone-cement interfaces and the recent finding that osteoclasts are derived from macrophages, these observations are significant in relation to the aetiology of bone-cement lucencies.
\end{abstract}

After total joint replacement radiolucent lines are often seen at the interface of bone and polymethylmethacrylate cement (PMMA). In this situation fibrous and chondroid elements have been observed histologically and small amounts of particulate PMMA and high molecular weight polyethylene (HMWPE) have been consistently reported (Charnley and Crawford 1968; Charnley 1970, 1975; Willert and Semlitsch 1976; Willert 1977; Charnley 1979). However, the precise aetiology of the line has not been established, nor has its clinical significance been fully defined.

The relationship between radiolucent lines and the failure of an arthroplasty remains obscure. The presence of a line, especially when it is wider than two millimetres, is often regarded as evidence of loosening. On the other hand, the incidence of loosening as a mode of clinical failure is consistently much lower than the incidence of radiolucent lines (Charnley 1970; Andersson, Freeman and Swanson 1972; Galante, Rostoker and Doyle 1975; Carlsson, Gentz and Stenport 1977; Collis 1977; Reckling, Asher and Dillon 1977; Beckenbaugh and Ilstrup 1978; Vanhegan, Dabrowski and Arden 1979; Galante 1980; Watts 1980). It is, therefore, generally appreciated that these lines do not necessarily indicate loosening or impending clinical failure.

If a mechanical phenomenon was the universal cause of radiolucent lines, some degree of loosening should be presumed in the presence of any radiolucency.
If, however, a chemical, thermal, or other biological phenomenon results in lucency, then the radiolucent line might not necessarily indicate movement at the interface.

In a series of patients who had undergone total knee arthroplasty we have been able to observe radiographically the interface between bone and PMMA cement and a separate interface between bone and a standard cobalt chrome ( $\mathrm{CoCr}$ ) cortical bone screw, both forming part of the same implant mass. Two separate bone interfaces within a single composite implant consisting of PMMA, a $\mathrm{CoCr}$ bone screw, and either a HMW polyethylene or a $\mathrm{CoCr}$ prostheses have thus been evaluated in each patient (Fig. 1). From one additional patient, with this configuration on the tibial side but undergoing revision for failure on the femoral side, histological specimens of these interfaces were obtained and studied. We believe that the results throw light upon the aetiology of radiolucent lines at the interface between bone and PMMA and suggest that the lines are not necessarily related to movement between the implant and the skeleton.

\section{METHODS AND MATERIALS}

Between late 1976 and 1979 a technique of implanting ICLH components was employed wherein $\mathrm{CoCr}$ bone screws were used as spacers in bone defects. This technique relies upon the screws to serve as supports for the component while PMMA polymerises between the implant and the bone so that the implant is properly aligned with respect to the weight-bearing axis of the knee (Fig. 1). Our operating

M. A. R. Freeman, MD, FRCS, Consultant Orthopaedic Surgeon The London Hospital, Whitechapel Road, London E1 2AD, England. G. W. Bradley, MD

2850 Sixth Avenue, Suite 103, San Diego, California 92103, USA.

P. A. Revell, PhD, MRCPath, Senior Lecturer and Honorary Consultant

Institute of Pathology, The London Hospital Medical College, Turner Street, London EI 2AD, England.

Requests for reprints should be sent to Mr M. A. R. Freeman.

(C) 1982 British Editorial Society of Bone and Joint Surgery 0301-620X/82/4104-0489 \$2.00 
technique during this period did not include injection of cement and thus our observations are not necessarily applicable to injected PMMA.

Twenty-eight knees in which this technique was used were identified. Five were lost to follow-up within 10 months; two were subsequently revised for loosening or infection; one had gross loosening as a result of a motor vehicle accident; and one was implanted in a malaligned position. In one patient radiolucent cement was used; therefore, no accurate observations could be made.

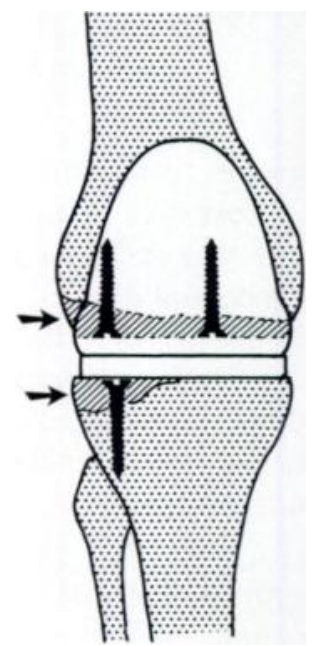

Fig. 1

Diagram of the technique wherein bone screws are used to help align prosthetic knee components in the presence of bone defects. Arrows indicate bone defects which have been filled with PMMA.

The remaining 18 knees (in 18 patients) were observed for periods ranging from 10 to 58 months, the average period being 32 months. The average age of these patients was 60.5 years (range 24 to 70 years) at the time of operation. There were six men and 12 women. The diagnosis was rheumatoid arthritis in nine patients and osteoarthritis in nine. Twelve right knees and six left knees were involved. Thirteen knees had the "screw-spacer" placed on the tibial side and seven knees had it on the femoral side, two having it on both sides. The tibial components were all manufactured of ultra-high molecular weight polyethylene and the femoral components were of cast $\mathrm{CoCr}$; the screws also were of $\mathrm{CoCr}$.

At the time of review, 17 of the 18 patients had satisfactory function of the evaluated knee. Radiography included oblique views and macroradiograms and all radiographs were assessed by at least two observers. The one patient with a clinically unsatisfactory knee had the "screw-spacer" on the tibial side, and subsequently required revision for collapse of the bone and loosening on the femoral side. At the time of revision, specimens were obtained from the tibial interfaces and were examined histologically.

\section{RESULTS}

In 17 of the 18 knees a radiolucent line was observed at the bone-cement interface. In only one knee was a similar lucency seen at the bone-screw interface. In four of the knees the lucency at the bone-cement interface was noted at one month; in eight, at six months, in four at one year, and in one at two years. Radiographs taken immediately after operation could not be evaluated satisfactorily because of the overlying plaster. In only one knee did a lucency exceed two millimetres; once present, none of the radiolucent lines increased substan- tially with time (as measured directly from plain radiographs); nor did any lucent line disappear. The single lucent line seen at the bone-screw interface was noted at one year on the same radiograph in which a lucency at the bone-cement interface could be seen.

In knees with a lucency at the bone-cement interface no relationship was noted between orientation of the cement surface and the presence of a line. Thus, a radiolucency was as likely to occur on a vertical as on a horizontal interface. Likewise, radiolucencies were as likely to occur next to cement relatively far from the joint as in cement close to the joint space.

\section{ILLUSTRATIVE CASE REPORT}

A 49-year-old white woman with rheumatoid arthritis had a left total knee arthroplasty in January 1976. A bone screw was used as a spacer because of a defect on the medial aspect of her tibia, and both components were implanted with PMMA. The postoperative course was uneventful, and the knee functioned satisfactorily. Three years later the patient complained of pain and a varus deformity of 10 degrees was noted. Radiographs revealed collapse of the medial femoral condyle (Figs 2, 3, and 4). Both components were subsequently revised. The femoral component was grossly loose, but all portions of the tibial component were clinically well fixed. Specimens of the tissue at the bone-implant interface were obtained from three zones (Fig. 5) and examined histologically.

Histological examination. Zone 1 was composed of fibrous tissue between PMMA and bone. Immediately subjacent to the PMMA, the fibrous tissue contained numerous macrophages and giant cells, and polyethylene and acrylic debris. Farther from the PMMA surface the fibrous tissue contained fewer macrophages; it also had less polyethylene and acrylic debris (Fig. 6). Zone 2 extended down from Zone 1 between the bone and the upper end of the screw (Fig. 7). It was similar in composition to the deeper region of Zone 1 but contained only very scanty macrophages. In Zone 3, around the tip of the screw, 15 millimetres from the PMMA surface, only a very thin fibrous membrane was present, and no macrophages were observed (Fig. 8). The bone adjacent to Zone 1 showed evidence of resorption lacunae and there was occasional active osteoclasis (Fig. 6). Adjacent to Zone 3 evidence of past resorption was present but no active osteoclasis could be seen (Fig. 8).

\section{DISCUSSION}

We believe that the basic observation made in this study, that a radiolucent line was nearly always seen at the bone-PMMA interface but only once at the bone- $\mathrm{CoCr}$ interface, casts light upon the aetiology of lucent lines.

In all the implants in this study the PMMA was solidly polymerised around the head of the screw. No fractures in the cement were seen on the radiograph and no fracture was found in the one case explored. Thus, had it moved, the PMMA-implant-screw mass would have moved as one unit. Since a lucent line was rarely seen around the screws, it follows that in almost every case (95 per cent) the PMMA was not moving grossly relative to the bone. Movement therefore could not have consistently caused the radiolucent lines between PMMA and bone. All the cases reported in this study were operated upon under a tourniquet and the bone was washed before PMMA was polymerised against it (but not injected into it). Thus, residual blood or debris at the 


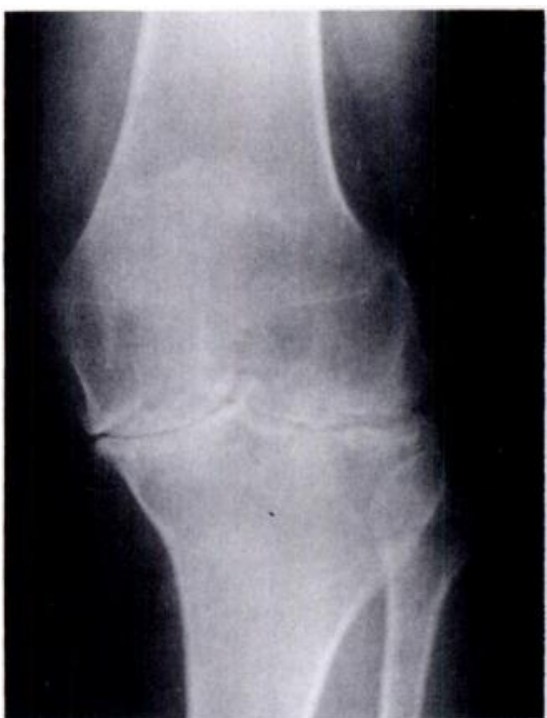

Fig. 2

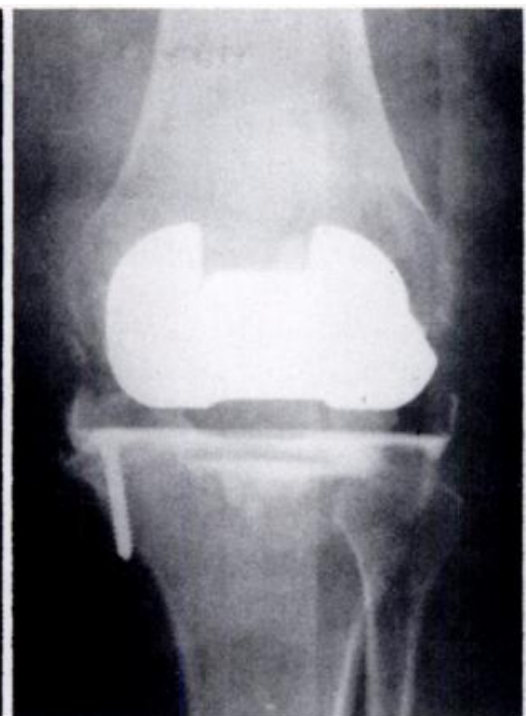

Fig. 3

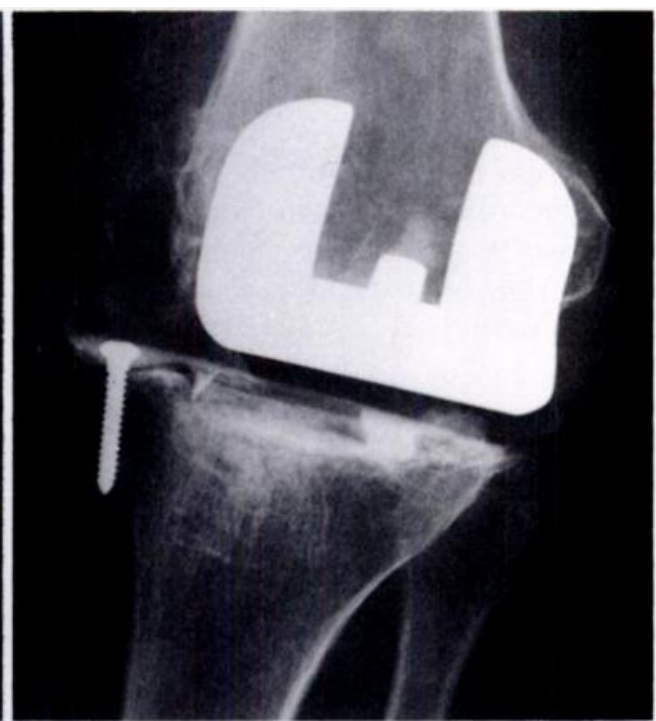

Fig. 4

Figure 2-Radiograph before operation, showing the defect in the medial tibial plateau. Figure 3-Radiograph taken soon after operation through the plaster, showing components in position and the use of a bone screw. Figure 4-Macroradiogram taken before revision, demonstrating lucency at bone-cement interface. No such lucency can be seen at the interface of bone and $\mathrm{CoCr}$ screw. Also note collapse of the medial femoral condyle and settling of the femoral component (compare with Fig. 3)

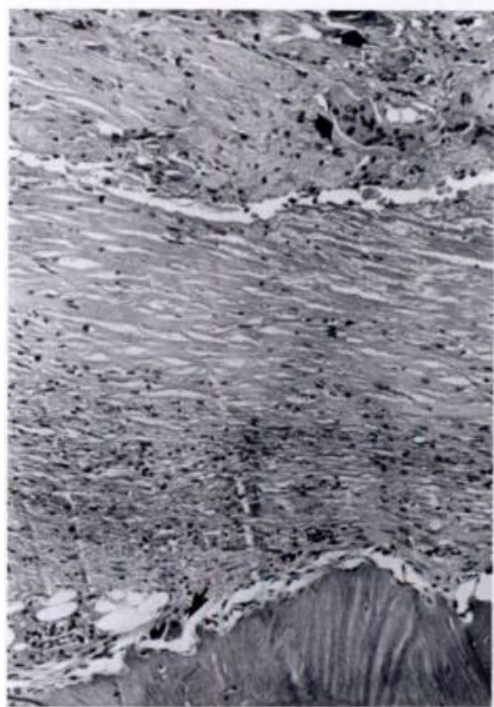

Fig. 6

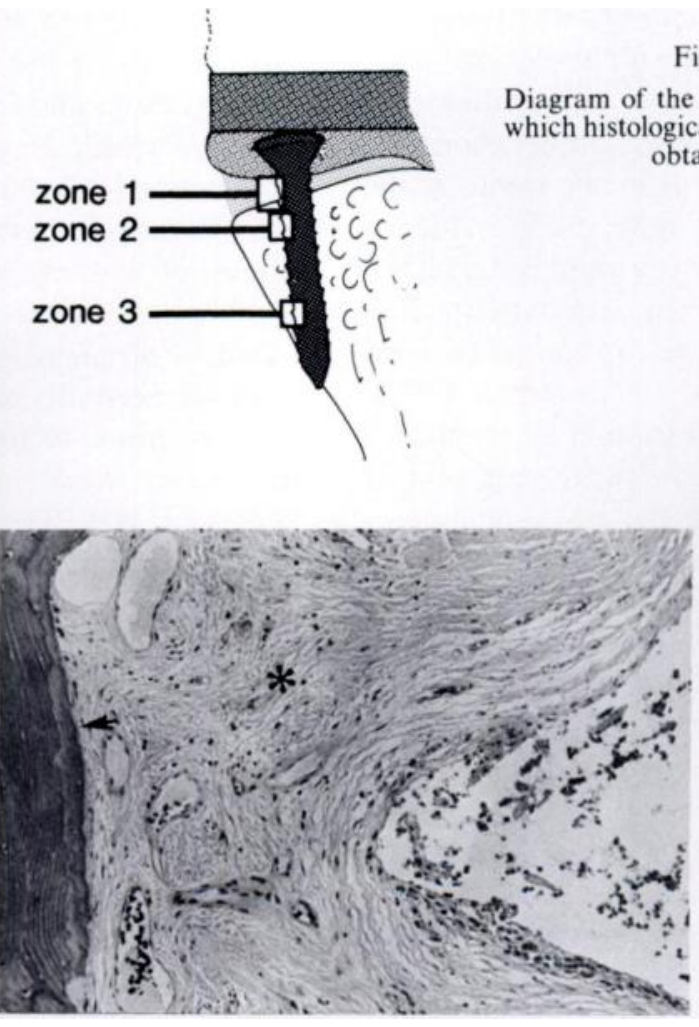

Fig. 7
Fig. 5

Diagram of the three zones from obtained.

Figure 6-Photomicrograph of the tissue between bone and PMMA (Zone 1) showing two distinct regions. The upper region contains numerous macrophages and giant cells containing PMMA and HDP debris (broad arrows). The lower region is less cellular fibrous tissue. Note osteoclastic resorption of bone (small arrow). Haemotoxylin and eosin, $\times 50$. Figure 7-Photomicrograph of the tissue between the upper part of screw thread and bone (Zone 2 ) showing vascular fibrous tissue $\left({ }^{*}\right)$ and a crenated margin to the bone indicating previous resorption (arrow). No osteoclasts or macrophages are present. Haematoxylin and eosin, $\times 50$. Figure 8-Photomicrograph of the tissue adjacent to the tip of the screw (Zone 3 ), showing spicules of bone and marrow separated from the screw by a fine fibrous membrane (arrows). The area of the screw is now a space with some blood present $\left({ }^{*}\right)$. Haematoxylin and eosin, $\times 50$. 
interface seem very unlikely to have been responsible for the radiolucent lines which were seen.

Polymerisation of PMMA is said to kill osteocytes immediately adjacent to the cement mass (Willert and Semlitsch 1976). Equally, however, the use of a highspeed drill or a self-tapping screw (both of which were employed in these knees) is said to cause bone necrosis (Collins 1953; Trueta and Cavadias 1955; DanckwardtLillieström 1969; Danckwardt-Lillieström, Lorenzi and Olerud 1970; Rhinelander 1972). Thus, although we have no histological evidence in our case for or against the early presence of dead bone, this possibility cannot be excluded at either interface. Had bone died at the interface, it might have been expected to undergo the "normal" fate of a bone infarct in continuity with vascularised cancellous bone (Catto 1977). An infarct one millimetre thick (as might have been present in these cases) undergoes vascular invasion with granulation tissue, followed by appositional new bone formation. Remodelling ensues until, a few weeks later, only new, living bone remains. At the distal $\mathrm{CoCr}$ interface our radiographic and histological observations suggest that the bone was never killed, or that it was killed and then replaced with living bone in this way (Fig. 8). By contrast, the bone at the PMMA interface, whether initially dead or alive, must have undergone resorption with subsequent fibrosis in the resultant gap to create a radiolucent line.

The explanation for the presence of a radiolucent line adjacent to PMMA may lie in the observation that numerous macrophages are present in the tissue at the bone-PMMA interface. There is now strong evidence that the macrophage, the foreign-body giant cell, and the osteoclast are the same cell type (Chambers 1980). It is generally appreciated that bone resorption is brought about by the osteoclast (Hancox 1972; Parfitt 1977). Beneath the cement mass in our example macrophages lay in thick fibrous tissue. In the deeper part of this tissue, about one millimetre from the PMMA, macrophages became scanty but nevertheless the adjacent bone showed evidence of active osteoclasis. Where the bonePMMA interface joined the bone-CoCr interface, at the neck of the screw, fibrous tissue persisted between the bone and the screw; but it was almost devoid of macrophages. At the tip of the screw, 15 millimetres from the cement, macrophages were absent, the fibrous tissue almost so, and the bone showed no evidence of active resorption. The tissue at the bone-PMMA interface was typical of that described at other such interfaces by Willert and Semlitsch (1976) and Charnley (1979); tissue at the tip of the screw was typical of that described by Collins (1953) and Hickman, Clarke and Jennings (1958) adjacent to intramedullary nails and screws used for the fixation of fractures. We believe that a similar histological appearance would have been present in all (or at least in 17) of our 18 cases, since radiologically visible soft tissue almost always separated PMMA from bone but rarely separated $\mathrm{CoCr}$ from bone.
We conclude that macrophages represent a response to PMMA (in the solid or debris form) but that they are induced little if at all by a surface of $\mathrm{CoCr}$, and that the extent to which bone at the interface is replaced by fibrous tissue is proportional to the number of macrophages at the interface.

The following hypothesis links these conclusions. Macrophages appear to be attracted to PMMA in a similar way as to other implant materials such as catgut (and $\mathrm{CoCr}$ in its particulate form). This reaction may be due to the presence of minute beads of PMMA shed from the surface or to the slow leaching of monomer (Amstutz 1970; Willert 1977). Since it is now known that the macrophage is the precursor of the osteoclast (Chambers 1980 ), it is not surprising that the bone immediately adjacent to a PMMA surface should undergo resorption and replacement by fibrous tissue containing macrophages and giant cells (Vernon-Roberts and Freeman 1977). In the absence of stimuli provoking continued macrophage activity (that is, continued osteoclasis) this membrane may become quiescent, thus producing the static, clinically benign radiolucent line.

By this hypothesis, it might be predicted that anything which stimulates macrophage activity would lead to progressive osteoclasis, a widening lucent line and, eventually, a loose prosthesis. Three stimuli are known to excite the macrophage: the products of cell death, bacteria and foreign particulate matter (Biozzi et al. 1957; Dicarlo, Haynes and Phillips 1963; Wagner, Iio and Hornick 1963; Nicol, Quantock and Vernon-Roberts 1966; Vernon-Roberts 1972; Stuart 1975). Thus, small degrees of movement at the bone-PMMA interface would be expected to kill some cells at this interface and to lead to progressive osteoclasis. Bacteria, even those which are normally non-pathogenic, would also lead, on this hypothesis, to progressive osteoclasis at a PMMA interface as would particulate debris (of, for example, PMMA, HMWPE, Teflon or metal). Naturally, cell death and the presence of bacteria or of debris may provoke macrophage activity and hence osteoclasis in the absence of PMMA; but it is now suggested that such osteoclasis will be more severe if these stimuli act upon the large pre-existing population of macrophages induced by the proximity of PMMA.

The presence of macrophages at the bone-PMMA interface is, as described by Charnley $(1979$, p. 34$)$ “. . . a tissue reaction which no implant surgeon can lightly dismiss". Indeed, we believe that it is the occurrence of macrophages at this interface which represents the essential factor in the response of bone to PMMA, leading to the presence of a radiolucent line at the bonePMMA interface and sometimes to clinically disastrous, progressive osteoclasis. In general it would seem obvious that materials implanted in immediate contact with living bone should not stimulate activity by macrophages with the potential of osteoclasis and subsequent loosening. 


\section{REFERENCES}

Amstutz HC. Complications of total hip replacement. Clin Orthop 1970;72:123-37.

Andersson GBJ, Freeman MAR, Swanson SAV. Loosening of the cemented acetabular cup in total hip replacement. J Bone Joint Surg [Br] 1972:54-B: $590-9$

Beckenbaugh RD, Istrup DM. Total hip arthroplasty. J Bone Joint Surg [Am] 1978;60-A:306-13.

Biozzi G, Halpern BN, Benacerraf B, Stiffel C. Phagocytic activities of the reticulo-endothelial system in experimental infections. In: Halpern BN, Benacerraf B, Delafresnaye JF, eds. Physiopathology of the reticulo-endothelial system. Oxford: Blackwell, 1957:204-24.

Carlsson AS, Gentz C-F, Stenport J. Fracture of the femoral prosthesis in total hip replacement according to Charnley. Acta Orthop Scand 1977;48:650-55.

Catto M. Ischaemia of bone. J Clin Pathol 1977;30 Suppl 11:78-93.

Chambers TJ. The cellular basis of bone resorption. Clin Orthop 1980;151 : 283-93.

Charnley J. Acrylic cement in orthopaedic surgery. Edinburgh and London: E \& S Livingstone Ltd, 1970.

Charnley J. The histology of loosening between acrylic cement and bone. J Bone Joint Surg [Br] 1975;57-B:245.

Charnley J. Low friction arthroplasty of the hip. Berlin: Springer-Verlag, 1979.

Charnley J, Crawford WJ. Histology of bone in contact with self-curing acrylic cement. J Bone Joint Surg [Br] 1968;50-B:228.

Collins DH. Structural changes around nails and screws in human bones. $J$ Pathol 1953;65:109-21.

Collis DK. Femoral stem failure in total hip replacement. J Bone Joint Surg [Am] 1977;59-A : 1033-41.

Danckwardt-Lillieström G. Reaming of the medullary cavity and its effect on diaphyseal bone. Acta Orthop Scand 1969; Suppl 128.

Danckwardt-Lillieström G, Lorenzi GL, Olerud S. Intramedullary nailing after reaming. Acta Orthop Scand 1970; Suppl 134.

Dicarlo FJ, Haynes LJ, Phillips GE. Effect of Mycobacterium phlei upon reticuloendothelial system of mice of different ages. Proc Soc Exp Biol Med 1963;112:651-4.

Galante JO. Causes of fractures of the femoral component in total hip replacement. J Bone Joint Surg [Am] 1980;62-A :670-3.

Galante JO, Rostoker W, Doyle JM. Failed femoral stems in total hip prostheses: a report of six cases. J Bone Joint Surg [Am] 1975;57-A:230-6.

Hancox NM. The osteoclast. In: Bourne GH, ed. The biochemistry and physiology of bone. 2nd ed. New York: Academic Press, 1972;1: 45-67.

Hickman J, Clarke EGC, Jennings AR. Structural changes in bone associated with metallic implants. J Bone Joint Surg [Br] 1958; 40-B: 799-803.

Nicol T, Quantock DC, Vernon-Roberts B. Stimulation of phagocytosis in relation to the mechanism of action of adjuvants. Nature 1966;209: $1142-3$.

Parfitt AM. The cellular basis of bone turnover and bone loss. Clin Orthop 1977;127:236-47.

Reckling FW, Asher MA, Dillon WL. A longitudinal study of the radiolucent line at the bone-cement interface following total joint-replacement procedures. J Bone Joint Surg [Am] 1977;59-B:355-8.

Rhinelander FW. Circulation of bone. In: Bourne GH, ed. The biochemistry and physiology of bone. 2nd ed. New York and London: Academic Press, 1972:1:2-77.

Stuart AE. The reticulo-endothelial system. In: Bell PGH, Coombs RRA, Lachmann PN, eds. Clinical aspects of immunology. 3rd ed. Oxford: Blackwell, 1975:365-409.

Trueta J, Cavadias AX. Vascular changes caused by the Küntscher type of nailing. J Bone Joint Surg [Br] 1955;37-B:492-505.

Vanhegan JAD, Dabrowski W, Arden GP. A review of 100 Attenborough stabilised gliding knee prostheses. J Bone Joint Surg [Br] 1979; 61-B: $445-50$.

Vernon-Roberts B. In : Harrison RJ, McMinn RMH, eds. The macrophage. Cambridge: Cambridge University Press, 1972.

Vernon-Roberts B, Freeman MAR. The tissue response to total joint replacement prostheses. In: Swanson SAV, Freeman MAR, eds. The scientific basis of joint replacement. Tunbridge Wells: Pitman Medical Publishing Company Limited, 1977:86-129.

Wagner HN Jr, lio M, Hornick RB. Studies of the reticulo-endothelial system (RES). II. Changes in phagocytic capacity of the RES in patients with certain infections. J Clin Invest 1963:42:427-34.

Watts HG. Total hip replacement in adolescents. Orthop Trans 1980;4:67.

Willert H-G. Reactions of the articular capsule to wear products of artificial joint prostheses. J Biomed Mater Res 1977:11:157-64.

Willert H-G, Semlitsch M. Problems associated with the anchorage of artificial joints. In: Chaldach M, Hofmann D, eds. Adiances in artificial hip and knee joint technology. Berlin, Heidelberg and New York: Springer-Verlag, 1976:325-46. 